\title{
Organizational and Educational Aspects of Primary Prevention of HIV/AIDS and Psychoactive Substance Dependence at a Medical School
}

\author{
Konstantin Zorin \\ A. I. Yevdokimov Moscow State University of Medicine and Dentistry \\ Moscow, Russia \\ zkv1000@yandex.ru
}

\begin{abstract}
The paper substantiates the significance of organizational and education aspects of the primary prevention of HIV/ AIDS and the psychoactive substance dependence among future doctors. Enhancement of the higher medical education system needs to seek new methods of education and upbringing. It may be desirable to include into the academic activity the lecture and practical studies of problem-solving and project nature, focused on promotion of moral and psychic health and on development of the ability to culturally educate on the development of healthy lifestyle, including the primary prevention of tobacco and alcohol use, drug abuse and HIV/ AIDS.
\end{abstract}

Keywords-health organization; healthy lifestyle, healthsaving behaviour; risk behaviour; higher medical education; primary prevention of drug abuse; primary prevention of HIV/AIDS

\section{INTRODUCTION}

The priority of humanistic values and the focus on psychological and educational environment required for the primary prevention of HIV/ AIDS and the psychoactive substances (PAS) use urge seeking new approaches in the education efforts. We have gained certain positive experience in such in-class work with medical students during their lecture and practical studies and calculate that this experience will become popular and will be employed by other departments of medical universities in Russia.

Specifically, during the spring and autumn terms in the 2016/ 2017 academic year the problem and project based studies were led with the students of the Dentistry Department and Medical Department, correspondingly. The proposed agenda included critical and lively problems concerning prevention of the viral hepatitis, HIV/ AIDS and the addictive and risk behaviour

II. ORGANIZATIONAL AND EDUCATION INNOVATIONS IN THE PRIMARY PREVENTION OF HIV/ AIDS AND THE PAS USE

The organizational-teaching innovations, for instance, include a problem-solving lecture with premeditated mistakes and a lecture-visualization. What is in the core of these classes?
During a problem-solving interview-based lecture (just as a seminar) an instructor creates and actualizes certain situation for students' discussion. Through the lecturer's efforts and/ or with students' assistance the new material is given in a form of problem-solving task where contemplations present the solution finding. The instructor together with students is moving gradually toward the desired goal as to a peculiar discovery, the cognitive process reminds search and exploratory activities. As the audience is engaged in the set task solution, the level of problematicity rises-students begin to identify and substantiate the detected contradictions and how to get them together, which already speaks for students' genuine feedback, the deficiency of which constitutes the major problem of any informative lecture-monologue. Accordingly, the problem-solving interview-based lectures are better tailored for the interactive (dialogue) training requirements.

In the beginning of a lecture with premeditated mistakes, the instructor, while being explicit about his intention, asks students to fix any mistakes they notice (diagnostic, therapeutic, psychological, ethical and other). The remainder of the class is dedicated to joint discussions. Such work arrangement impels to listen more attentively and allows assessing the degree of understanding of the presented material.

A Visualized lecture features certain systematized and methodologically treated oral information converted into a visual form - commenting of visual or audio visual pieces (video, diagrams, figures and such). As an aid for the education process, the UNESCO Department of the A. I. Yevdokimov Moscow State University of Medicine and Dentistry (MGMSU) http://кафедраюнеско.pф has placed on its web page for self-guided work the webinars and presentations of Professor K. G. Gurevich, M.D., the Russian Academy of Sciences.

Unlike lectures, it is appropriate in practical training to employ different problemistic techniques-group brainstorming, discussions and business games that we actively apply during practical classes in the discipline "Healthy Lifestyle" with the purpose of primary prevention of the PAS use [1] [2]. 
The projects and training events based on the 'harm reduction' approach refer to the major preventative efforts. The approach is aimed at reducing the harmful effect of drug addiction without requiring from the user to completely forego PAS or other risk behaviour (such as commercial delivery and receiving sexual services). The probability of infection, drug overdose or of other harm lowers when using sterile instruments (needles, injectors, WFI, desinfectants, etc.), the opioid substitution therapy, free condoms, information materials and accessibility of the HIV rapid testing, etc. Nevertheless, there are many opponents of such programs, who are raising strong and argumented objections [3].

How can a medical student gain insight into such complex and sensitive issues, triggering mixed public reaction? We assume the situational-role (business) games are of assistance here. Essentially, this technique implies an improvised playing out of a situation that simulates some activity and challenges that arise from it. Several students act certain parts. The same situation can be played out several times to give all the participants an opportunity to play different parts.

Employment of the situation-role (business) games is appropriate for clarification of details, beneficial and negative impacts of the 'harm reduction' programs. For instance, the participants split into three groups 'Lawyers', 'Opponents' and 'Judges'. Taking their turn, the first bring forward pro arguments, the second argue against, while the third find verdict ('conviction').

From the experience of our classes, productive disputes run high around problems of the principal direction in combating the drug addiction, of the injectable route of HIV/ AIDS infection. The 'Lawyers' defend liberal views - it is useless to prohibit 'free love' and fight the urge to 'get kicks' and, therefore, the propagation of so-called 'safe-sex' is necessary as a free distribution of 'sterile needles, syringes and condoms'. The 'Opponents', in turn, stand their conservative ground, advocating education within traditional moral values as the basis of the development of health saving model of sexual and reproductive behaviour.

The 'Judges' are young people, usually 17-20 years of age. Arguing with the peculiar to this age mental outlook and life perception, they usually admit that the substitution of 'hard' drugs with 'softer' ones and the free distribution of sterile tools impel users to use those, without doubt, according to students' expression, 'on a freebie'. The harm reduction programs, on one hand, reduce the likelihood of infection and drug overdose, but again, they give some sort of 'absolution' and generate delusion of safety, thereby heightening the dangerous interest to psychoactive compounds and casual relationships.

The educational business game helps the class to see the simple truth-"Addiction must not be indulged"; "Many sexual partners imply higher risk, regardless of protectors"; "No contraceptive guarantees hundred per cent against the STD and HIV infection"; "Monogamous marital relations minimize the risk of being infected".
Intellectually gifted students most often also offer thorough synopsis. The 'harm reduction' programs are being compared to palliative care that eliminates particular clinical disease, while total abstinence from cacoetheses answers the healthy lifestyle and is akin to etiopathogenetic treatment, directly dealing with the cause and patterns of medical condition. Thus, the etiopathogenetic treatment is better than symptomatic therapy.

It is important that in the result of such business games some of the 'Lawyers' fall into line with their 'Opponents'. In our view, this speaks for the emphatic psychological and educational effect, the reappraisal of values and building of an active personality position.

Other business games, including the "Doctor-Patient" game, after the fashion of the "What? When? When?" intellectual game show, also demonstrate good results during practical classes addressing the problems of primary preexposure prophylaxis. Provided with specific information, students actively discuss what should be undertaken, and if specialized medical consultation is required, or laboratory and instrumental examination, additional data, etc. The team members pass their collective decision to the moderator, who, based on the benchmark solution, provides the requested data or informs on changes in patient's status.

In the game "Case Conference" students' roles are distributed in accordance with the number of the participants. Each participant's role can be played out by several students.

The role games without an exact scenario do not dictate clear-cut benchmark actions and present an adopted to the medical university learning environment version of a psychodrama. The methodology is designed not so much for the development of specific knowledge as for acquisition of personal experience, valuable communicative skills. Having no exact scenario, the participants are given chance to play true-life roles. An example is playing of different psychological situations of a doctor's communication with a patient during their talk on bad health habits and addictive behaviour.

To our opinion, during the lecture-based and practical studies of the problem-solving and project nature, students get more familiar with important points: the mechanisms of building addictions are basically identic. All people addicted to something are united by the strive to get quickly and effortlessly rid of their spiritual vacuum, mental anguish and strain, while any addiction specifically allows to do violence to conscience, to negate reason, to change personal experiences, to escape memory and tune out unpleasant reality [4].

\section{OUTREACH EDUCATIONAL PROGRAMS FOR PREVENTION OF RISK BEHAVIOUR AND HIV/AIDS}

The significance of preventive and outreach educational programs promoting positive thinking and health saving behaviour is obvious across-the-board. Jointly with the Russian Orthodox Church were developed programs for prevention of risk behaviour and HIV/ AIDS for children and youth "LadYa" (for 13-17 years of age), "Water of Life 
(Zhivaya voda, for junior students) and "Way Home" (for students). Over 10,000 people in ten regions of Russia completed these programs. The programs have been endorsed by the team of skilled instructors, psychologists, psychiatrists and narcologists with an active participation of experts of the Department of Clinical Psychology of the A. I. Evdokimov MGMSU, headed by Professor N. A. Sirota, Doctor of Medicine and Psychological Sciences [5] [6] [7] [8].

The core target of the programs is education based on family values, marital fidelity, withdrawn from drugs and other bad health propensities. Having learned these lessons, youth will be able to build self-control of their behaviour in a responsible manner.

In the course of class discussions of the problems of HIV/ AIDS prevention and addictive behaviour, students draw the conclusion that many risk factors are rooting in the core of personality and in the inmost of psyche. Existential problems, the loss of sense of life, clear or covert violation of moral rules and values lead to spiritual or emotional crisis and to physical symptoms afterwards. The correlation between person's physical, psychic and spiritual health is strong and reciprocal. Accordingly, disease of any organ is capable of aggravating the general emotional condition, disordering intellection and behaviour. This is a vicious loop.

Our experience has shown that a group discussion presents an effective technique of dialogue arrangement. This is an organized instructor-led ventilation of problems in class, intended to identify students' opinions, ideas and experiences and to cross-reference them in direct communication, to better understand the personal, social and psychological personality of each. The elaborated rules of rhetorical strategies are as follows:

- Commitment to a problem solution, rather than to creation of a conflict.

- Not to speak at great length, to keep work within the planned time.

- To speak on relevant issues only.

- To try to understand opponents' position.

- To be able to hear to the end.

- Not to give vent to controversial fervour, to remember that the opposer is not a foe in life.

- When disagreeing with someone, not just to tell what is assumed wrong, but to propose constructive solution.

Here are the standard topics of group discussions: "The moral foundations of healthy lifestyle and of disease prevention", "Patterns of sexual behaviour and their implication in the propagation of drug abuse and HIV/ AIDS", "Correlation between the PAS use and the liability to transmissible diseases", etc.

\section{CONCLUSION}

Consequently, the problem-solving and project-based lectures and practical classes for medical students prove to be the most advanced in terms of organizing the primary prevention of HIV/ AIDS and PAS use. It is advisable to apply active training methods for the promotion of healthy lifestyle through educational techniques. The educative programs should include special packages focused on strengthening of moral and mental health, evolving the ability to conduct the cultural and educational work pertaining to the preservation of the physical, mental and spiritual health, including the prevention of tobacco smoking, alcohol and drug addiction, HIV/AIDS.

\section{REFERENCES}

[1] N. V. Kudryavaya, E. M. Ukolova, A. S. Molchanov, N. B. Smirnova K. V. Zorin, Physician-teacher in a changing world: tradition and innovation / Ed. Acad. Academy of Medical Sciences, Prof. N.D. Yushchuk, M., 2005, p. 131.

[2] N. V. Kudryavaya, K. V. Zorin, N. B. Smirnova, E. V. Anashkina Psychology and Pedagogy in medical education: the textbook for students of universities/ Prof. N.V. Kudryavaya (ed.), M.: Knorus, 2018, p. 318.

[3] Healthy lifestyle and disease prevention / Ed. N. D. Yushchuka, I.V Maeva, K.G. Gurevicha, M.: Pero, 2012, pp. 270-272.

[4] K. V. Zorin, Spiritual aspects of the disease // Medical Assistance, 2008, No. 4, pp. 47-50.

[5] N. A. Sirota, V. M. Yaltonsky, T. V. Volkova, Motivational consultation of children and adolescents at risk in relation to the use of psychoactive substances. Training toolkit, M., 2004. N. A. Sirota, V.M. Yaltonsky, Application and implementation of programs for the rehabilitation and prevention of addictive behavior as an important task of the Russian clinical psychology // Medical psychology in Russia: an electronic scientific journal, 2012, No. 2.

[6] N.A. Sirota, V.M. Yaltonsky, Effective prevention programs for drug addiction and other forms of addictive behavior, M.: Rainbow Processing Center, 2004, p. 192.

[7] V.M. Yaltonsky, N.A. Sirota, T.V. Vorobyova, On the necessity of preventive education for young people and the prevention of substance abuse in the context of HIV prevention // Preventing HIV infection among injecting drug users and other vulnerable groups in the Russian Federation: Review of regional experience, News bulletin 2009, No. (1), pp. 5-7. 